\title{
OBLIGACIONES EMPRESARIALES EN MATERIA DE Seguridad Social y Salud en las Contratas Y Subcontratas de Obras o Servicios
}

\author{
Salcedo Beltrán, Maria Carmen \\ Universidad de Valencia
}

Siendo que las contratas y subcontratas de obras y servicios se han convertido en la modalidad de descentralización productiva más utilizada en la actualidad, se erige como primordial la cuestión relativa a las obligaciones en materia de seguridad y salud de los distintos sujetos que intervienen en ellas. Las mismas aparecen enunciadas en el art. 24 de la Ley 31/1995, de Prevención de Riesgos Laborales, agrupándose bajo el título genérico de coordinación de actividades empresariales, y van encaminadas a que todos los empresarios se coordinen respecto de las medidas de prevención a adoptar cuando se comparte un mismo lugar de trabajo y que, en el caso de que se concierte una contrata o subcontrata, el empresario principal vigile además el cumplimiento de la normativa por parte de los contratistas.

Taking into account that building and service contracts and subcontracts habe become the most common mode of decentralisation used nowadays, the issue related to the obligation in health and safety matters for the individual has become of primary importance: These are found in section 24 act 31/1995, Prevention of Labour Risk, under the generic title of the coordination of business activities, the objective being that the contractors comply to the prevention measures to be adopted in a common workplace and in the case of a contract or subcontract being made, the principal contractor should check that these norms are fulfilled by the contractor.

Palabras clave: obligaciones empresariales, contratas o subcontratas, empresario principal, seguridad y salud, descentralización productiva

Key words: contractor obligations, contracts and subcontracts, principal contractor; bealth and safety. productive decentralisation 
1. INTRODUCCIÓN: EL DEBER DE PREVENCIÓN DEL EMPRESARIO EN MATERIA DE SEGURIDAD Y SALUD

Uno de los deberes básicos del empresario en la relación laboral es el deber de protección empresarial en materia de seguridad y salud respecto de los trabajadores $^{1}$. Se concibe como la obligación del empresario de proteger a los trabajadores frente a los riesgos profesionales, y su importancia es relevante puesto que fundamentalmente la evitación y no acaecimiento de contingencias laborales dependerá de cómo el empresario haya planificado su actividad preventiva, la cual no ha de consistir en una mera serie de actuaciones formales de un conjunto de obligaciones sino que ha de tratarse de una protección y prevención eficaces (Exposición de Motivos de la LPRL).

En base a esto, el empresario se erige en el principal obligado pues es el titular de su centro de trabajo, por lo que en la medida en que sobre él recae el poder de tomar todas las decisiones, también ha de ser su responsabilidad que el lugar de trabajo así como todas las condiciones en que se desempeña la prestación laboral revistan la seguridad que exige la ley ${ }^{2}$.

Con carácter general el deber de protección se encuentra recogido en el art. 14.1 de la LPRL y su reconocimiento en la legislación sobre seguridad y salud en el trabajo no es novedoso pues a lo largo de la OSHT se determinaban las distintas obligaciones del empresario, fijando en el párrafo segundo del art. 7 lo que se podría considerar como la obligación genérica de protección al disponer que el empresario está obligado a "adoptar cuantas medidas fueren necesarias en ordèn a la más perfecta organización y plena eficacia de la debida prevención de los riesgos que puedan afectar a la vida, integridad y salud de los trabajadores al servicio. de la empresa".

Junto a esa norma se ha de citar como plasmación legal del deber de protección al ET pues lo tiene en cierta manera fijado aunque desde la perspectiva del trabajador, pues, por un lado, el art. 4.2 establece en su letra d) el derecho del trabajador "a su integridad física y a una adecuada política de seguridad e higiene", y, por otro, el art. 19 el de "una protección eficaz en materia de seguridad e higiene".

1. Se ha señalado en este sentido que este deber junto al de la protección de la capacidad de trabajo del trabajador y la protección de su bienestar, a través de la protección asistencial, constituyen los. llamados deberes < de protección> en sentido amplio, cuyo origen hay que situarlo en el histórico sen-tido tuitivo del Derecho del Trabajo. En AA.VV. (Dir. SALA FRANCO, T.): Derecho del Trabajo. Valencia, 1999 ( $12^{2}$ ed.). Tirant lo Blanch. Págs. 516 y 517.

2. Vid ALARCON CARACUEL, M.: "Los deberes del empleador en materia de prevención". En AA.VV. (Coord. SALVADOR PEREZ, F.): La seguridad y salud en el trabajo en la nueva Ley de Prevencion de: Riesgos Laborales. Sevilla, 1997. Junta de Andalucia. Pág. 72. 
Ese deber de seguridad tiene un contenido muy amplio y complejo puesto que se materializa en toda una serie de obligaciones específicas. En este estudio se hará referencia a la concreción del mismo en el supuesto de que se trate de una contrata o subcontrata de obras o servicios pues se trata de la modalidad de descentralización productiva típica, cuya utilización va en aumento con el paso del tiempo en la medida en que responde a la plasmación de la tan en boga en los últimos años <estrategia de flexibilidad de la empresa $>3$, con lo que conviene tener claros los distintos papeles que tienen que asumir cada uno de los empresarios que forman parte de ella.

\section{Características de las Obligaciones}

Con carácter previo al análisis de cada una de las obligaciones que tienen los distintos empresarios considero conveniente señalar los caracteres de las mismas. Fundamentalmente son los siguientes:

$1^{\circ}$. Con auténticas obligaciones jurídicas que como tales constriñen al empresario a adoptar toda una serie de actitudes en orden a su cumplimiento. Ello supone también la existencia de un correlativo derecho subjetivo en favor del trabajador que viene reconocido en el art. 14.1 de la LPRL ("los trabajadores tienen derecho a una protección eficaz...") y en los arts. 4.2 d) ("los trabajadores tienen derecho (...) a su integridad física...") y 19.1 del ET ("el trabajador, en la prestación de sus servicios, tendrá derecho a una protección eficaz...").

$2^{\circ}$. Son obligaciones a cargo del empresario, es decir, es él quien debe llevar a cabo todas las tareas necesarias para la protección de los trabajadores y la ausencia de contingencias profesionales y que sobre él ha de recaer el coste de todas esas actuaciones pues tal como señala el art. 14.5 de la LPRL "el coste de las medidas relativas a la seguridad y la salud en el trabajo no deberá recaer en modo alguno sobre los trabajadores". Del mismo modo, si en alguna de las tareas a realizar se necesita tiempo de los trabajadores, se utilizará el de la jornada laboral y, en caso de no ser posible, se descontará. Por tanto, asunción total por parte del empresario del coste directo o indirecto del deber de prevención.

3. Ejemplos prácticos de esta afirmación han sido mostrados por MARTín ARTILES en Flexibilidad y relaciones laborales. Estrategias empresariales y acción sindical. Madrid, 1995. Consejo Económico y Social. Págs. 21 a 50 . Sobre su funcionamiento y régimen jurídico vid, entre otros, CRUZ VILLALON, J.: "Descentralización productiva y responsabilidad laboral por contratas y subcontratas". RL, 1992, $\mathrm{n}^{\circ} 2$; MONEREO PEREZ, J.L.: La responsabilidad empresarial en los procesos de subcontratación: puntos criticos. Madrid, 1993. Ibídem; y GARCÍA PIQUERAS, M.: Régimen juridico de las responsabilidades empresartales en las contratas y subcontratas de obras y servicios. Valencia, 1998. Tirant lo Blanch. 
Conviene precisar no obstante qué se entiende por empresario. Siguiendo el art. 1.2 del ET "todas las personas, físicas o jurídicas, o comunidades de bienes que reciban la prestación de servicios de las personas referidas en el apartado anterior, así como de las personas contratadas para ser cedidas a empresas usuarias por empresas de trabajo temporal legalmente constituidas" o la definición similar que da la Directiva 89/391/CEE en su art. 3 (y que no acoge la LPRL en el art. 4 dedicado a las definiciones) como "cualquier persona física o jurídica que sea titular de la relación laboral con el trabajador y tenga la responsabilidad de la empresa $y / 0$ establecimiento". De lo que se trata de concretar es de que no hay que relacionar el concepto laboral de empresario con el mercantil, puesto que en este último es necesario que se persiga una finalidad de lucro lo que, por contra, no se requiere para el primero bastando, como ha precisado la jurisprudencia ${ }^{4}$, con que el trabajo se preste en su beneficio, no siendo necesario que sea comerciante ni las notas de habitualidad ni profesionalidad.

Siguiendo con el concepto de empresario, se ha de considerar también como sujeto obligado a las Administraciones Públicas, pues tal como apunta la LPRL en su Exposición de Motivos, esta ley nace con "vocación de universalidad", lo que supone que su ámbito se extienda lo máximo posible 5 .

$3^{\circ}$. Son obligaciones dinámicas, lo que supone que si se quiere dispensar una protección correcta y adecuada a los trabajadores dichas obligaciones han de renevarse y adaptarse a las circunstancias de cada momento o lugar. Así lo recoge el art. 14.1 in fine de la LPRL que dispone que "el empresario desarrollará una acciôn permanente con el fin de perfeccionar los niveles de protección existentes y dis-

4. STS de 2 de diciembre de 1987 (Ar. 9274).

5. Esta extensión del ámbito es calificada por la propia LPRL en la Exposición de Motivos como una

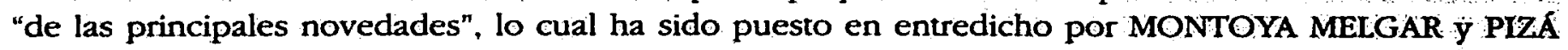
GRANADOS porque este aspecto ya lo preveian con anterioridad: la Directiva 89/391/CEE (DOCE L 183, de 29 de junio de 1989) que en el art. 2 dispone que se aplicarā "a todos los sectores de actividades, públicas o privadas (actividades industriales, agrícolas, comerciales, administrativas, de servicios, educativas, culturales, de ocio, etc.)"; el art. 3 a) del Convenio $n^{\circ} 155$ de la OIT (Convenio de 22 de junio de 1981 (Ratificado por Instrumento de 26 de julio de 1985 (BOE de 11 de noviembre de 1985)) que señala que "la expresión ramas de actividad económica abarca todas las ramas en las que hay trabajadores empleados, incluida la administración pública", y lo mismo díspone la letra b) del mismo artículo al definir que "el término trabajadores abarca todas las personas empleadas, incluidos los empleadós públicos". Incluso el art. 1 de la OSHT extendía su ámbito al mismo que el del Sistemá de la Seguridad Social. En Curso de Seguridad y Salud en el trabajo. Madrid; 1995. McGraw-Hill. Pág 73. En el mismo sentido vid, entre otros, GONZÁLEZ ORTEGA, S, Y APARICIO TOVAR, J: Comentarios a la Ley 3419995 de Prevención de Riesgos Laborales. Madrid, 1996. Trotta. Pág. 59. 
pondrá lo necesario para la adaptación de las medidas de prevención señaladas en el párrafo anterior a las modificaciones que puedan experimentar las circunstancias que incidan en la realización del trabajo", lo que es lógico puesto que una visión estática de las distintas obligaciones en la que se cumpliera mediante la realización de un acto único dejaría al trabajador desprotegido y más si se tiene en cuenta que hoy en día se introducen de forma reiterativa cambios tecnológicos en los puestos de trabajo que exigen que la protección sea renovada y actualizada a las nuevas necesidades que pueden tener los trabajadores frente a los cambios producidos o frente a nuevas circunstancias personales que presenten.

$4^{\circ}$. Son obligaciones de medios, es decir, que se cumplen si se despliega toda una actividad preventiva. Esta caracterización no es pacífica entre la doctrina laboralista, puesto que existen autores que estiman que son de resultado con lo que las distintas obligaciones se cumplen si aclemás de lo dicho anteriormente no se produce ningún accidente o enfermedad profesional' ${ }^{(1}$, fundamentando su posición en lo siguiente:

a) La protección se logra evitando el daño, es decir, eliminando el peligro, y no sólo llevando a cabo la labor preventiva.

b) El art. 14.1 de la LPRL señala que "los trabajadores tienen derecho a una protección eficaz en materia de seguridad y salud en el trabajo", y es la utilización de ese adjetivo la que conlleva que para que la protección sea correcta no han de producirse lesiones a los trabajadores, lo que exige que el empresario tiene que impedir los accidentes.

c) El mismo artículo anterior en su párrafo segundo señala que "en cumplimiento del deber de protección, el empresario deberá garantizar la seguridad y salud de los trabajadores a su servicio". Es la exigencia de esa garantía la que conlleva la consecuencia de que las distintas obligaciones son de resultado, pues al igual que en el caso anterior, se cumple si no ha acaecido ningún accidente.

d) Por último, se apunta también que el art. 14 de la LPRL en su párrafo segundo señala que "en el marco de sus responsabilidades, el empresario realizará la prevención de los riesgos labores...", lo que supone la evitación del riesgo, es decir, que no ocurra el accidente, pues en caso contrario las obligaciones serian reparadora.

6. GONZÁlleZ ORTEGA, S. Y APARICIO TOVAR, J.: Comentarios a la Ley 31/1995 de Prevención de Riesgos... op. cit. Págs. 107 y 108; GONZÁlEZ LABRADA, M.: Seguridad y salud en el trabajo y responsabilidad contractual del empresario. Barcelona, 1996. CEDESC. Págs. 357 a 364; SEMPERE NAVARRO, A.V., GARCLA BLASCO, J., GONZALEZ LABRADA, M. Y CARDENAL CARRO, M.: Derecho de la seguridad $y$ salud en el trabajo. Madrid, 1996. Civitas. Pág. 159; CARDONA RUBERT, M.B.: Datos santtarias y relactón laboral. Valencia, 1999. Tirant lo Blanch. Págs. 14 y 15. 
De acuerdo con esta interpretación, sólo se exoneraría el empresario si no ocurren accidentes, no haciendo distinciones entre si ha cumplido o no su actividad preventiva, puesto que sólo se atiende al resultado. $\mathrm{Y}$ es fundamentalmente esta no distinción la que ha llevado a otro sector de la doctrina a estimar que las obligaciones son de medios ${ }^{7}$, puesto que una aplicación correcta de la seguridad y salud en el trabajo y de la prevención de los riesgos profesionales ha de valorar si el empresario ha cumplido o no, es decir, si ha llevado a cabo una actividad diligente en cuanto a la evitación del accidente. De ignorarlo, no se estaría incentivando a los empresarios al cumplimiento de la normativa en materia de seguridad y salud, ya que resultarían responsables llevaran a cabo o no una actividad preventiva, de manera que se estaria plasmando una responsabilidad objetiva que conllevaría en ocasiones a situaciones injustas pues se haría responsable a un empresario sin tener en cuenta si ha realizado o no lo prescrito por la normativa de salud laboral.

Por tanto, en mi opinión la teoría de que las obligaciones empresariales en materia de seguridad y salud son de medios es la más acorde con el espíritu de la LPRL que es el de instar a los empresarios a que cumplan y tomen medidas para prevenir los accidentes, precisando, tal como ha señalado la doctrina que se inclina por esta teoría, que se tratan de obligaciones de medios muy amplias, puesto que no sólo se cumple tomando las medidas concretas según cada situación o puesto de trabajo, sino que se ha de realizar toda una labor mediante la que se adopten todas las medidas necesarias y posibles para evitar accidentes.

Por último, quiero señalar que no toda la doctrina laboralista se ha inclinado por una de estas dos interpretaciones sino que han habido posiciones intermedias, como la de GONZÁLEZ-POSADA MARTíNEZ que al respecto ha señalado que a la hora de caracterizar las distintas obligaciones no se puede hacer de forma unitaria respecto de todas ellas sino que dependerá de la prestación que tenga que realizar el empresario en cada caso: si se trata, por ejemplo, de la paralización de la actividad en caso de riesgo grave e inminente, se está comprometiendo al empresario a la actividad y al resultado; sin embargo, si se trata de la evaluación de riesgos, el empresario se compromete al desarrollo de la diligencia y esfuerzo exigido por el legislador. Por consiguiente, si como se ha dicho en

7. SALA FRANCO, T. Y ARNAU NAVARRO, F.: Comentarios a la Ley de Prevención de Ríesgos Laborales. Valencia, 1996. Tirant lo Blanch. Pág. 79; ALARCON CARACUEL, MR: 'Los déberes del empleador en materia de prevención... "op. cit. Păg. 69; MONTOYA MELGAR, A Y PLÁ GRANADOS: J.: Curso de seguridad y salud en el trabajo... op. cit Pág. 85 y ALFONSO MELLADO, GIE: Responsabilidad empresarial en materia de seguridad y salud laboral. Valencia, 1998. Tiñnt lo Blanich; Págs. 19 a 22. 
páginas anteriores el deber de prevención empresarial es muy amplio, habrá que atender a qué obligación concreta tiene que realizar para calificarla de medios o de resultado 8 .

$5^{\circ}$. Son obligaciones autónomas, es decir, que el empresario o sujetos responsables en cumplirlas han de llevarlas a cabo con independencia de que las obligaciones de trabajar y retribuir se cumplan, en la medida en que en ocasiones éstas no se darán y, sin embargo, se tendrá que seguir garantizando la seguridad e integridad física de los trabajadores en virtud del mandato constitucional ${ }^{9}$, lo que da muestra de la importancia de la materialización de ésta, que juega desconectada de las incidencias que puedan aparecer en la relación laboral, siendo su finalidad la protección máxima del trabajador.

$6^{\circ}$. Son obligaciones de naturaleza jurídico-privada. En relación con la naturaleza jurídica de las distintas obligaciones se ha planteado entre la doctrina laboralista también una discordancia en cuanto a si ésta es solamente jurídico-privada, es decir, que se tiene en virtud de la existencia de un contrato de trabajo o, por contra, que se trata de obligaciones que junto con la anterior naturaleza privada también la tienen pública.

Entre los autores que han optado por la primera interpretación, que son la mayoria ${ }^{10}$, han señalado de forma tajante que el origen de la obligación de seguridad, que como ya se ha apuntado anteriormente, engloba a toda una serie de obligaciones concretas entre las que se encuentran las que se analizarán en las páginas siguientes en materia de contratas o subcontratas, se encuentra en el con-

8. En "La prevención de riesgos laborales: funciones, contenido y efectos". Ponencia del VII Congreso Nacional de Derecho del Trabajo y de la Seguridad Social (ejemplar multicopiado). Valladolid, 24 y 25 de mayo de 1996. Pág. 20.

9. Así lo han apuntado SEMPERE NAVARRO, A.V., GARCÍA BLASCO, J., GONZÁlEZ LABRADA, M. Y CARDENAL CARRO, M.: Derecbo de la seguridad y salud en el trabajo... op. cit. Págs. 157 y 158.

10. GONZÁLEZ ORTEGA, S.: "Derecho a la salud y control de los trabajadores". RL, 1990, n 5-6. Pág. 82; APARICIO TOVAR, J.: "Las obligaciones del empresario de garantizar la salud y la seguridad en el trabajo". REDT, 1991, $n^{\circ}$ 49. Pág. 8; SEMPERE NAVARRO, A.V., GARCÍA BLASCO, J., GONZÁLEZ LABRADA, M. Y CARDENAL CARRO, M.: Derecho de la seguridad y salud en el trabajo... op. cit. Pág. 158; SALA FRANCO, T. Y ARNAU NAVARRO, F.: Comentarios a la Ley de Prevención de riesgos... op. cit. Pâg. 110; ÁlVAREZ DE LA ROSA, M.: "El deber de protección y los servicios de prevención de riesgos laborales". DS, 1996, n 1. Pág. 42; ALARCÓN CARACUEL, M.: "El impacto de la Ley 31/1995 sobre el contrato de trabajo". En AA.VV. (Coord. ESCUDERO RODRÍGUEZ, R.): La ley de prevención de Riesgos Laborales. Málaga, 1997. Consejo Andaluz de Relaciones Laborales. Págs. 45 a 47; ALFONSO MELLADO, C.L.: Responsabilidad empresarial en materia de seguridad y salud... op. cit. Págs. 20 y 21. 
trato de trabajo, siendo por tanto una obligación de naturaleza jurídico-privada, es decir, que se ha de cumplit frente al trabajador o trabajadores que llevan a cabo la prestación laboral. Reconocen la existencia de un interés público en el cumplimiento del deber de prevención, lo que se materializa en que el contenido de esa obligación se inserte en el contrato de trabajo ope legis, es decir, que en su contenido haya una fuerte intervención pública.

Frente a esta interpretación, se encuentra la que estima que el deber de prevención tiene junto a la naturaleza jurídico-privada también una naturaleza jurídico-pública ${ }^{11}$, señalando que es un deber que se tiene frente a los trabajadores y frente al Estado puesto que las condiciones de seguridad y salud afectan a uno de los principios rectores de la política social y económica del país (art. 40.2 de la CE).

En mi opinión, la obligación de seguridad se ha de interpretar en el sentido de que se trata de una obligación de carácter privado, es decir, que se tiene frente al trabajador o frente a otros empresarios, y si bien hay una fuerte connotación pública en él, no es mayor que la que se pueda tener en otros aspectos de la relación laboral como pueden ser la duración de la jornada de trabajo o las formas contractuales.

$7^{\circ}$. Por último, son obligaciones parcialmente asegurables. Las distintas obligaciones a que se hará referencia en el punto siguiente exigen toda una serie de actuaciones por parte de los distintos empresarios que forman parte de una contrata o subcontrata. En caso de incumplimiento se les derivan, siguiendo el art: 42 de la LPRL, toda una serie de responsabilidades, que pueden ser administrativas (que son las que fija la propia normativa en materia de seguridad y salud), penales (que se pueden derivar de la comisión de un delito específico contra los derechos de los trabajadores -arts. 316 a 318 del CP- o de la comisión de un delito genérico de homicidio o lesiones como consecuencia de una infracción laboral -arts. 138 y 142 ó 147 del CP), civiles (contractual -art. 1101 del CoC-, extracontractual -art. 1902 del CoC- o derivada del CP -art. 116 del CP)- o derivada del recargo de prestaciones económicas (art. 123 de la LGSS).

11. FERNÁNDEZ MARCOS, L.: La seguridad e bigiene del trabajo como obligación contractual $y$ : como deber público. Madrid, 1975. Servicio de Publicaciones del Ministerio de Trabajo. Păgs. 69 a 71 y 125 a 130; MONTOYA MELGAR, A. Y PIZÁ GRANADOS, J: Curso de seguridad y salud en el trabajo... op. cit. Págs. 78 y 79; MORENO VIDA, M.N.: "La seguridad y salud en el trabajo: el deber de preven-ción de riesgos profesionales. Un análisis desde la perspectiva de la Directiva $89 / 391 /$ CEE)". En AAVV. (Coord. MONEREO PÉREZ, J.L.): La reforma del mercado de trabajo y de la seguridad social y sáliud! laboral. Granada, 1996. Servicio de Publicaciones de la Universidad de Granadà. Pagsi 555 a 559. 
En la medida en que tanto las responsabilidades administrativas como penales tienen una naturaleza sancionadora, no pueden ser objeto de aseguramiento. Sin embargo sí que lo pueden ser, tal como permite el art. 15.5 de la LPRL ${ }^{12}$, la responsabilidad civil contractual o extracontractual que se pueda derivar del incumplimiento del deber de prevención, puesto que su naturaleza es indemnizatoria teniendo como objetivo el resarcimiento individual del trabajador que ha sufrido un perjuicio o daño causado y materializado.

En cuanto al recargo de prestaciones, la cuestión relativa a su aseguramiento está relacionada con la controvertida determinación de su naturaleza jurídica. En la medida en que el estudio de esos aspectos de forma completa excederían la extensión del presente trabajo me limitaré a señalar que en mi opinión la naturaleza de este concepto es indemnizatoria pues, por un lado, su finalidad es la de resarcir al trabajador que se ha visto dañado en el desempeño de su trabajo como consecuencia de un incumplimiento en materia de seguridad y salud y, por otro, porque se considera una responsabilidad compatible con la administrativa (art. 42.3 de la LPRL) que tiene naturaleza sancionadora, con lo que no se podría predicar la compatibilidad de ambos conceptos si el recargo es considerado también sancionador $^{13}$.

12. Expresamente dispone que se "podrán concertar operaciones de seguro que tengan como fin garantizar como ámbito de cobertura la previsión de riesgos derivados del trabajo, la empresa respectos de sus trabajadores, los trabajadores autónomos respecto a ellos mismos y las sociedades cooperativas respecto a sus socios cuya actividad consista en la prestación de su trabajo personal".

13. Optan también por esta interpretación, entre otros, BLASCO PELLICER, A. y MORRO LOPEZ, J.J.: "Puntos críticos en torno al recargo en las prestaciones por falta de medidas de seguridad e higiene en el trabajo. Reflexiones en torno a la incidencia de la Ley de Prevención de Riesgos Laborales". TrS, 1995, n 60. Págs. 36 y 37; GARCÍA MURCIA, J.: "Régimen de responsabilidades en materia de seguridad y salud en el trabajo". En AA.VV. (Coord. CASAS BAAMONDE, M.E., PALOMEQUE LÓPEZ, M.C. Y VALDÉS DAL-RÉ, F.): Seguridad y salud en el trabajo. Madrid, 1997. La Ley-Actualidad. Págs. 224 y 225; GONZÁLEZ ORTEGA, S. Y APARICIO TOVAR, J.: Comentarios a la Ley de Prevención de Riesgos... op. cit. Pág. 277; SÁNCHEZ CUBEL, D.: Todo sobre la nueva Ley de Prevención de Riesgos Laborales. Barcelona, 1996. Praxis. . Págs. 186 y 187. En contra se han pronunciado, entre otros, SALA FRANCO, T. Y ARNAU NAVARRO, F.: Comentarios a la Ley de Prevención... op. cit. Pág. 188; ALFONSO MELLADO, C.L.: Responsabilidad empresarial en materia de seguridad y salud... op. cit. Pâg. 34. Como de naturaleza híbrida o mixta, participando de las dos anteriores, se han manifestado MONEREO PÉREZ, J.L.: El recargo de prestaciones económicas por incumplimiento de medidas de seguridad e higiene en el trabajo: Madrid, 1992. Civitas. Págs. 30 y ss.; PURCALLA BONILLA, M.A.: "Notas sobre la naturaleza juridica del recargo de prestaciones por incumplimiento de medidas de seguridad e higiene en el trabajo". RTSS, 1995, abril-mayo. Pág. 81; MONTOYA MELGAR, A. Y PIZÁ GRANADOS, J.: Curso de Seguridad y Saludd... op.cit. Pág. 310. 
Respecto a su aseguramiento estimo que pese a ser una indemnización no puede ser objeto del mismo, pues está encuadrado para que sea el empresario el que la pague con el fin de constreñirle a adoptar las medidas necesarias para que no vuelva a acaecer el accidente o enfermedad profesional ${ }^{14}$.

\section{OBLIGACIONES EMPRESARIALES EN LAS CONTRATAS Y SUBCONTRATAS DE OBRAS O SERVICIOS}

Las distintas obligaciones que tienen los empresarios cuando concurren con otros en materia de seguridad y salud en el trabajo vienen fijadas en el art. 24 de la LPRL. Bajo el título genérico de coordinación de actividades empresariales se establece que labores tienen que realizar en común o individualmente, dependiendo de la existencia o no de un negocio jurídico entre ellos. En la medida en que cada una de ellas presenta unos perfiles diferentes se analizarán de forma separada.

\subsection{LA COOPERACIÓN INTEREMPRESARIAL}

La primera conducta a observar por parte de los empresarios que comparten en el desempeño de su labor un mismo centro de trabajo viene prevista en el párrafo primero del art. 24 de la LPRL, que al respecto señala que "deberán cooperar en la aplicación de la normativa sobre prevención de riesgos laborales".

Esta previsión es fiel reflejo de lo dispuesto en el art. 17 del Convenio $n^{\circ} 155$ de la OIT relativo a la Seguridad e Higiene en el trabajo y medio ambiente de trabajo ${ }^{15}$ y en el art. 6.4 de la Directiva $89 / 391 /$ CEE relativa a la aplicación de las medidas para promover la mejora de la seguridad y de la salud de los trabajadores en el trabajo16, con lo que en este aspecto se han seguido de forma correcta las directrices internacionales y comunitarias.

14. Vid en este sentido también MOLINER TAMBORERO que argumenta la no posibilidad de aseguramiento pese a ser indemnización en que lo prohibe expresamente el art. 123.2 de la LGSS. En "La responsabilidad civil empresarial derivada del incumplimiento de las previsiones contenidas en la Ley 31/1995, de prevención de riesgos laborales". Al, 1996, no 19. Pág: 397.

15. "Siempre que en dos o más empresas desarrollen simultáneamente actividades en un mismo lugar de trabajo tendrán el deber de colaborar en la aplicación de las medidas previstas en el presente Convenio":

16. "Sin perjuicio de las demás disposiciones de la presente Directiva, cuando en un mismo lưgar de trabajo estén presentes trabajadores de varias empresas, los empresarios deberán cooṕerar en la aplicación de las disposiciones relativas a la seguridad, la higiene y la salud, así como, habida cuenta el tipo de actividades, coordinarse con vistas a la protección y prevenciớn de riesgos prófesíonales; infótmarse mutuamente de dichos riesgos, e informar a sus trabajadores respectivos y/o sus representantes: 
Se trata de una imposición a la que le es indiferente si entre dichos empresarios existe una relación jurídica o jerárquica ${ }^{17}$, puesto que lo único que se erige como requisito primordial es que desempeñen su trabajo teniendo un lugar común. Por tanto, es un principio general que debe regir todas las situaciones en las que se comparte el centro de trabajo, que es lo que ocurre, entre otros supuestos, en las contratas o subcontratas.

Con carácter previo al estudio del contenido de ese deber de cooperación considero conveniente realizar una precisión. Así, de una lectura literal del párrafo primero del art. 24 de la LPRL, se deduce que esa cooperación se ha de llevar a cabo cuando se comparta un mismo centro de trabajo. En este sentido la redacción ha sido incorrecta, puesto que la noción de <centro de trabajo> es, siguiendo el art. 1.5 del ET, muy acotada, ya que como ha señalado la doctrina lo realmente importante y que está en la base de su finalidad son las condiciones materiales, locales, medios e instrumentos de trabajo, el espacio y el entorno físico que rodea la prestación de trąbajo ${ }^{18}$.

En vista de esto, lo adecuado es estimar que bajo esa expresión se está haciendo referencia al lugar de trabajo, cuyo ámbito objetivo es mucho más amplio que el anterior, permitiendo que la protección se aplique de forma más correcta y siendo además la expresión que utilizan la normativa internacional y comunitaria señalada anteriormente ${ }^{19}$.

La forma de materializar esa cooperación no viene señalada en el párrafo, disponiendo simplemente que se deberán establecer los medios de coordinación que sean necesarios en cuanto a la protección y prevención de riesgos laborales ${ }^{20}$. Deberá consistir en una actuación conjunta para poder valorar los posibles riesgos

17. En mi opinión GARCÍA NINET y VICENTE PALACIO (En AA.VV. (Dir. GARCÍA NINET, J.I.: Lecciones sobre la Ley de Prevención de Riesgos Laborales. Castellón, 1997. Universitat Jaume I. Pág. 115) parten erróneamente de la idea de que el centro de trabajo tiene que pertenecer necesariamente a una de las empresas que desempeña el trabajo junto con las otras, lo cual no se deriva necesariamente del precepto y puede no darse en la realidad como ha señalado GOERLICH PESET (En "Coordinación de actividades empresariales y prevención de riesgos laborales". AL, 1997, n 8. Pág. 131) aportando, a modo de ejemplo, la concurrencia de unas empresas en un polígono o en un edificio de oficinas, donde ringuna de las que trabaja es la titular del centro.

18. FERNÁNDEZ MARCOS, L.: "Responsabilidad del empresario principal respecto de contratas y subcontratas en materia de seguridad e higiene en el trabajo". AL, 1992, n 1. Pág. 9.

19. En este sentido se ha pronunciado, entre otros, GOERLICH PESET, apoyando su posición en la STS (UD) de 18 de abril de 1992, que consideró como centro de trabajo un poste del tendido de una línea eléctrica. En "Coordinación de actividades empresariales... " op. cit. Págs. 128 y 129.

El propio Convenio $\mathrm{n}^{\circ} 155$ de la OIT define en el art. 3 c) la expresión <lugar de trabajo> como la que abarca "todos los sitios donde los trabajadores deben permanecer o adonde tienen que acudir por razón de su trabajo, y que se hallan bajo el control directo o indirecto del empleador". 
que se puedan originar de su prestación laboral, ya se deriven de su actuación individualizada o en común, cōn el fin de evitarlos o, en su caso, adoptar las medidas necesarias para aminorar sus consecuencias, estableciendo al efecto medidas conjuntas y sistemas de seguridad compartidos. Dicha actuación deberá llevarse a cabo antes de iniciar el trabajo y actualizarse cada vez que se incorpore un nuevo sujeto al lugar de trabajo, lo que con bastante frecuencia se dará, por ejemplo, en el supuesto de las contratas en el sector de la construcción pues en un principio se comienzan con una relación entre una empresa principal y un contratista, y a continuación la última va celebrando e incorporando al lugar de trabajo sucesivas subcontratas.

Pese a que literalmente el art. 24.1 de la LPRL no prevé la información entre los empresarios, a mi juicio está implícita dentro de la coordinación entre ellos.

Una forma de viabilizar esa práctica conjunta sería a través de la representación especializada en materia de seguridad y salud en el trabajo, es decir, los Delegados de Prevención o el Comité de Seguridad y Salud. De hecho, la propia LPRL en el art. 39.3 prevé la posibilidad de que estos realicen reuniones conjuntas con el fin de facilitar la coordinación que los empresarios tienen encomendada, pero se deja en todo caso a discreción del empresario el utilizar esa vía ${ }^{21}$, lo que ha de ser objeto de crítica puesto que una redacción impositiva habría garantizado su realización.

Esa actuación conjunta se vería optimizada por la posibilidad que recoge el art. 21 del RSP de constituir servicios de prevención mancomunados "entre aquellas empresas que desarrollen simultáneamente actividades en un mismo centro de trabajo, edificio o centro comercial". En mi opinión, dada la realidad de que existan numerosas empresas en un mismo lugar de trabajo y que incluso algunas de ellas no conozcan al resto de empresas, la constitución de estos servicios de prevención les pone en contacto y permite una mejor coordinación entre todos 22 .

El mismo párrafo que está siendo objeto de análisis en este punto prevé una obligación de información por parte de los empresarios a sus trabajadores que van a desempeñar la labor en ese centro, previsión que, a mi juicio, es obvia ya que

20. Vid VALVERDE ASENCIO, A.J: La responsabilidad administrativa laboral en los supuestös de pluralidad de empresarios. Valencia, 1997. Tirant lo Blanch. Págs. 100 a 103.

21. GOERLICH PESET, J.M.: "Coordinación de actividades empresariales... “ op. cit. Pấg. 133.

22. Se trata de un sistema que, al igual que el anterior, es voluntario y respecto del mismo ha apuntado CRUZ VILLALÓN que si bien su conversión en obligatorio podría convertirlo en contraproducen: te sí que sería conveniente que, al menos, en ciertos sectores, actividad o empresas en laś que se superara un determinado número de empleados se hiciera. En "Outsourcing Contratas y subcontratas". Ponencia presentada en el X Congreso Nacional de Derecho del Trabajo y de la Seguridad Social. Zaragoza, 28 y 29 de mayo de 1999. Ejemplar multicopiadø. Pág. 16. 
viene prevista en el art. 18.1 de la LPRL que, recoge la obligación de informar por parte del empresario a sus trabajadores en relación con los riesgos para la seguridad y la salud, las medidas y actividades de protección y las medidas de emergencia.

Por tanto, la primera obligación a observar por los empresarios que compartan un mismo lugar de trabajo, con independencia de la relación jurídica que entre ellos exista, es la de cooperar con el fin de prevenir los posibles riesgos existentes, debiendo actuar de forma conjunta en todos los aspectos referentes a la seguridad y salud. Que no sea necesaria esa relación jurídica no quiere decir que no se aplique, de existir ésta, a las empresas que la tenga.

3.2. EL TRASPASO DE INFORMACIÓN E INSTRUCCIONES ADECUADAS POR EL EMPRESARIO TITULAR DEL CENTRO DE TRABAJO

La segunda obligación a observar, en este caso sólo por el empresario titular del centro de trabajo, que podrá ser empresario principal o no según que haya celebrado una contrata u otro negocio jurídico, viene recogida en el apartado segundo del art. 24 de la LPRL que señala al respecto que éste deberá adoptar las medidas necesarias para que aquéllos otros empresarios que desarrollen actividades en su centro de trabajo "reciban la información y las instrucciones adecuadas, en relación con los riesgos existentes en el centro de trabajo y con las medidas de protección y prevención correspondientes, así como sobre las medidas de emergencia a aplicar, para su traslado a sus respectivos trabajadores".

En este supuesto la posición del empresario titular se ve reforzada en lo que se refiere a las obligaciones que se tienen que llevar a cabo, puesto que tiene respecto de los demás empresarios una posición que sobresale lo que le hace objeto también de mayores responsabilidades.

Con carácter previo al análisis de esta obligación quiero aclarar que, en mi opinión, las obligaciones que en este supuesto le son imputadas al empresario titular no supone que las del resto de empresarios se vean relegadas de las suyas, es decir, que la obligación de coordinación del párrafo primero del art. 24 sigue rigiendo las relaciones entre todos los empresarios pese a que uno de ellos haya adquirido cierto protagonismo 23 . Lo que sí estarán en todo caso es más relativizadas pero nunca anuladas.

23. Vid VALVERDE ASENCIO, A.J.: La responsabilidad administrativa laboral en los supuestos... op. cit. Pág. 100, y G.OERLICH PESET, J.M.: "Coordinación de actividades empresariales... " op. cit. Pág. 134. 
Fundamentalmente en este apartado se está obligando al empresario titular en dọs sentidos:

a) Por un lado, debe facilitar información al resto de empresarios que están desempeñando su trabajo en el centro del que él es titular sobre los riesgos existentes, las medidas de protección y prevención, así como las medidas de emergencia respecto de su centro de trabajo a aplicar, lo que es lógico puesto que como titular es conocedor de todas esas circunstancias y de las condiciones a aplicar en la medida en que ha debido realizar la correspondiente evaluación de riesgos y en función de los resultados de ésta ha adoptado toda una serie de medidas.

En este traspaso de información es necesaria la cooperación de los destinatarios de ésta, ya que, de no existir, las actividades en materia de prevención que pudiera realizar el titular resultarían ineficaces, puesto que la información, como he señalado, se limita al centro de trabajo que detenta, con lo que es necesaria la coordinación de los otros empresarios para que comuniquen los posibles riesgos que se pueden derivar de su actuación y de los instrumentos y materiales que utilicen e introduzcan en el lugar de trabajo. Con ello se reafirma, por tanto; la idea de que los párrafos primero y segundo del art. 24 se complementan y no se excluyen.

Posteriormente, esa información deberá a su vez ser transmitida por el resto de empresarios a sus trabajadores que son, en suma, los sujetos que fundamentan esa coordinación y a los que se pretende proteger.

b) $\mathrm{Y}$, por otro, debe dar instrucciones adecuadas en relación con la materias señaladas en la letra anterior. La interpretación de esta obligación plantea un problema en cuanto a los destinatarios de ella. Si se sigue una interpretación literal de la norma, de ella se deduce que los destinatarios, al igual que en el anterior supuesto, son el resto de empresarios que prestan sus servicios en el centro de trabajo de la empresa principal. Sin embargo, el art. 12 de la Directiva 89/391/CEE dispone que "el empresario deberá garantizar que los trabajadores de las empresas exteriores que intervengan en su empresa o establecimiento hayan recibido las ins:trucciones pertinentes en lo que respecta a los riesgos para la seguridad y la salud. durante su actividad en su empresa y/o establecimiento".

Por tanto, entre dichas normas se observa una discordancia sobre los sujetos: que deben recibir dicha información, puesto que de la LPRL se deduce que son los empresarios que comparten el lugar de trabajo, mientras que de la Directiva los destinatarios son los trabajadores de estas empresas. 
En este sentido GONZÁLEZ ORTEGA y APARICIO TOVAR se han inclinado por interpretar el párrafo de acuerdo con lo señalado por la Directiva, añadiendo que la impartición de esas instrucciones conlleva una obligación de formación a esos trabajadores en relación con los riesgos de su centro de trabajo y las medidas para combatirlos $^{24}$.

En mi opinión esta interpretación no se puede derivar del dictado del artículo y considero que las precauciones y obligaciones que deba tomar el empresario principal han de moverse en el nivel del resto de empresarios, dejando a estos últimos que viabilicen el asesoramiento y formación con sus propios trabajadores, puesto que la relación directa con el empresario es la que mejor adaptará las distintas directrices señaladas por el empresario titular y la que tendrá en cuenta las especificaciones y observaciones de cada trabajador, que sólo son conocidas por su empresario.

En resumen, si cuando se coincide en un mismo lugar de trabajo, existe un empresario que tenga el carácter de titular frente a una o todas las empresas que allí trabajan; él mismo tendrá que llevar a cabo unas obligaciones adicionales de información e impartición de instrucciones como consecuencia de ser el mejor conocedor del espacio donde se desarrollará la actividad laboral. El resto de empresarios, pese a que el titular del centro tiene unas específicas obligaciones, no se ven relegados de las obligaciones señaladas en el art. 24.1 de la LPRL, puesto que su incursión conlleva la aparición de nuevos riesgos, que han de ser objeto de prevención conjuntamente.

\subsection{LA VIGILANCLA DEL EMPRESARIO PRINCIPAL}

El párrafo tercero del art. 24 de la LPRL recoge una obligación cuyo destinatario es el empresario principal que ha celebrado una contrata o subcontrata de obras o servicios, consistiendo en que debe llevar a cabo una vigilancia sobre los contratistas y subcontratistas en el cumplimiento de la normativa de prevención de riesgos laborales.

Conviene aclarar que pese a que en las obligaciones señaladas en los puntos anteriores no se hacía referencia expresa a esa condición, esto no supone que los empresarios que tuvieran el carácter de principal no resultaran obligados sino muy al contrario, puesto que se encuentran enunciadas con carácter general respecto de cualquier sujeto que tenga la condición de empresario y que comparta con otros el mismo lugar de trabajo. Por tanto, se trata de obligaciones que se solapan unas con otras y de ninguna manera se excluyen.

24. En Comentarios a la Ley 31/1995, de Prevención de Riesgos... op. cit. Pág. 163. 
Siguiendo con la delimitación del supuesto de hecho del párrafo tercero del art. 24 de la LPRL, la oblígación de vigilancia regirá mientras dure la contrata, es decir, durante el tiempo en que los contratistas o subcontratistas estén desempeñando su labor en la empresa principal, no pudiendo extrapolarse a otros períodos de tiempo puesto que en tal caso sería imposible materializar este control por estar fuera del alcance de las posibilidades de la empresa principal.

Se trata de una obligación que no se ha de dirigir hacia los trabajadores de los contratistas o subcontratistas sino respecto de estos últimos, ya que todo lo que tenga que ver con sus trabajadores es obligación de su propio empresario, puesto que la relación de dependencia se encuentra establecida entre el trabajador y el contratista, debiendo éste observar, controlar y vigilar el cumplimiento de las normas respecto de sus trabajadores, quedándole eso sí al empresario principal, y en referencia con los contratistas o subcontratistas, la obligación de vigilancia como consecuencia del desempeño de la labor en su centro de trabajo.

En cuanto a los sujetos obligados, se plantea el problema de qué ocurre cuando se da una cadena de sucesivos contratistas o subcontratistas en el desempeño de unas tareas. Considero acertada la interpretación de GOERLICH PESET que señala que tal obligación afecta a todos los sucesivos empresarios que puedan adquirir la condición de principales, utilizando como argumento fundamental el hecho de que comparten un mismo lugar de trabajo ${ }^{25}$. También se justifica en la existencia de una coordinación empresarial que pone en contacto a todos los empresarios, pues esa planificación conjunta inicial y periódica de los riesgos y de su prevención hace que a la hora de exigir responsabilidades se pueda encadenar al resto de empresarios, ya que han participado en la elaboración del plan de seguridad.

Una vez delimitado parcialmente el supuesto de hecho de este párrafo conviene definir en qué consiste este deber in vigilando. Tal como se ha señalado el empresario principal ha de vigilar que el contratista cumpla las obligaciones que le atribuye la normativa de prevención de riesgos laborales con el fin de prevenir los posibles incumplimientos y consecuentes accidentes de trabajo que pueden acaecer, de los que resultará responsable.

Se ha considerado que esta obligación de vigilar lleva implícita un deber in eligendo, es decir, comprobar que los contratistas y subcontratistas reúnen las condiciones para poder cumplir sus obligaciones ${ }^{26}$. En mi opinión, este cuidado en ele-

25. En "Coordinación de actividades empresariales... " op. cit. Pág: 148.

26. Vid SÁNCHEZ CUBEL, D.: Todo sobre la nueva Ley de Prevención de Riesgos... op. cit Pag 109. 
gir no se deriva sólo de este párrafo del art. 24 de la LPRL sino de los anteriores, puesto que desde el momento en que se va a compartir un lugar de trabajo se ha de prestar atención a los empresarios que van a prestar su labor en la medida en que de su actuación dependerá también la seguridad de sus trabajadores y, por tanto, su responsabilidad.

\subsubsection{El concepto de propia actividad}

Con anterioridad se ha dicho que todos los que celebren una contrata o subcontrata de obras o servicios y que pasen a ser empresarios principales van a resultar obligados a observar esta conducta de vigilancia, lo que no es exactamente cierto, puesto que siguiendo la lectura del párrafo tercero del art. 24 de la LPRL se dispone que esta previsión sólo se aplica a las contratas o subcontratas en las que se cumpla el requisito de la propia actividad.

Es una expresión cuya interpretación ha sido calificada por la mayoría de la doctrina como confusa y de difícil precisión ${ }^{27}$, llegando incluso algunos autores a señalar ha señalado la necesidad de no prestar atención a esta inclusión y de tenerla por no puesta ${ }^{28}$. A mi juicio esta interpretación no es admisible puesto hay que distinguir claramente dos planos: uno el de lo dispuesto por la ley y otro el de lo que hubiera sido correcto en esa disposición. Que se haya insertado esa expresión es criticable y más con los precedentes del art. 42 del ET. Pero que esto sea así no permite optar por considerarla no existente, ya que si el legislador la ha puesto esa parece ser su intención y a ella hay que atenerse. Por tanto, la previsión del art. 24.3 de la LPRL se ceñirá sólo a las contratas y subcontratas de propia actividad ${ }^{29}$.

En cuanto al significado del requisito, la doctrina ha seguido distintas líneas interpretativas, las cuales en ocasiones son totalmente dispares, mientras que en otras guardan cierta proximidad.

27. Vid, entre otros, MARTIN VALVERDE, A.: "Responsabilidad empresarial en caso de subcontrata de obra y servicios". En AA.VV. (Dir. BORRAJO DACRUZ, E.): El Estatuto de los Trabajadores. Comentarios a las leyes laborales. Tomo VII. Madrid, 1982. Edersa. Pág. 241. y GOERLICH PESET, que la califica como "una noción difusa". En "Coordinación de actividades empresariales... " op. cit. Pág. 143.

28. Así se ha pronunciado GONZÁLEZ ORTEGA, S. Y APARICIO TOVAR, J.: Comentarios a la Ley. $31 / 1995$ de Prevención... op. cit. Págs. 164 y 165.

29. En este sentido se pronuncian también, entre otros, GARCIA MURCIA, J.: "Régimen de responsabilidades en materia de seguridad y salud... " op. cit. Pág. 227 y SÁNĊHEZ CUBEL, D.: Todo sobre la nueva Ley de Prevención... op. cit. Págs. 108 y 109. 
Así, parte de la doctrina parecía inclinarse porque fuera interpretado en senti do amplio, es decir, que tòdas o casi todas las obras o servicios que contrate o subcontrate la empresa principal tendrán cabida dentro de esa expresión, salvo aquellas labores que estén totalmente desconectadas de la actividad de la comitente ${ }^{30}$.

Otros autores, entre los que destaca RODRÍGUEZ PIÑERO ${ }^{31}$, intentaron fijar algunos criterios - un total de tres- a los que atenerse cuando se analizara la cuestión, haciendo referencia dos de ellos, el locativo y el temporal, a aspectos externos al ciclo productivo de la empresa principal, es decir, que la determinación de si existía entre la contratista o subcontratista propia actividad se realizara atendiendo bien al lugar dónde los trabajadores prestaran efectivamente su trabajo, puesto que se presumía que si se trabajaba en la factoría del comitente se trataba de una actividad propia de la empresa en cuyos locales se trabajara, bien a la frecuencia con la que se acudía a la contrata, partiendo de la idea de que si se recurre con carácter normal y perdurable, se puede intuir que éstas son necesarias para el ejercicio de la actividad de la empresa comitente y por tanto la contrata corresponde a la propia actividad de la empresa principal.

El tercer y último criterio que al respecto señaló hacía referencia, a diferencia de los dos anteriores, no a aspectos externos de la actividad contratada o subcontratada, sino que atendía a la naturaleza misma de la obra o trabajo prestados entre el comitente y el contratista.

Si bien en ocasiones pudieron resultar útiles, en mi opinión los dos primeros siguen la misma línea interpretativa amplia que se ha señalado anteriormente, puesto que es difícil que no se presente alguno de ellos cuando se desempeñe uña contrata, al mismo tiempo que según el que se adopte se puede llegar a una decisión positiva o negativa en cuanto al desempeño de una de ellas ${ }^{32}$.

30. Por esta interpretación se han inclinado MARTÍN VALVERDE, A.: "Responsabilidad empresarial en caso de subcontrata..." op. cit. Pág. 244; MARTÍNEZ EMPERADOR, R.: El Estatuto de los Trabajadores y la responsabilidad empresarial en caso de subcontratas de obras y servicios. IES. Madrid, s/f. Servicio de Publicaciones del Ministerio de Trabajo. Pág. 7; ALONSO OLEA, M. Y BARREIRO GONZÁLEZ, G.: El Estatuto de los Trabajadores. Texto, comentarios y jurisprudencia. Madrid, 1995 (42 ed.). Civitas. Pág. 143.

31. En "La regulación protectora del trabajo en contratas". RPS, $1972, n^{\circ} .93$. Págs. 38 y ss.

32. Piénsese, por ejemplo, en relación con el criterio locativo, que existen contratas como las quèe tienen por objeto el mantenimiento de líneas eléctricas, que pese a que se desarrollan fuera del espacio físico donde la empresa principal desempeña su actividad, son consideradas que cumplen el concepto de propia actividad (vid la STS (UD) de 18 de abril de 1992 (Ar. 4849). Por contra, algunos trabajos efectuados dentro de sus locales pueden ser considerados como que no cumplen el requisito de la propia actividad, como ocurre con el servicio de vigilancia (STS (UD) de 18 de enero de 1995 (Ait. 514). 
Tras los recientes pronunciamientos judiciales que se han emitido sobre la cuestión y que posteriormente serán objeto de análisis, algunas opiniones doctrinales giran, a la hora de fijar si concurre la nota de la propia actividad, en torno a la idea de conexión con el ciclo productivo que ya había señalado RODRÍGUEZ PIÑERO en su tercer criterio, es decir, sugieren que se ha de atender a qué labores desempeña la empresa principal y a la relación que existe entre ellas y la que desempeña la contratista, siendo lo determinante que la actividad que lleva a cabo la contratista corresponda principalmente al objeto de la actividad de la empresa principal33.

De las primeras resoluciones que intentaron clarificar la cuestión se ha de citar la STS de 18 de enero de 1995 (Ar. 514) que, en unificación de doctrina, señaló que ha de entenderse por propia actividad "las obras o servicios que pertenecen al ciclo productivo de la misma, esto es que forman parte de las actividades principales de la empresa (...)". Con este primer acotamiento se aclaraba bastante la cuestión puesto que se daría la propia actividad entre una empresa contratista y una empresa principal si la primera realizaba labores que se podían incardinar dentro del ciclo productivo de la segunda. El problema se encontraba en que en la propia sentencia se incluían otra serie de puntualizaciones que enturbiaban la primera puesto que apuntaba también frases como que "más que la inherencia al fin de la empresa, es la indispensabilidad para conseguirlo lo que debe definir el concepto de propia actividad" así como que "nos encontrariamos ante una contrata de este tipo cuando de no haberse concertado ésta, las obras y servicios debieran realizarsé por el empresario comitente so pena de perjudicar sensiblemente su actividad empresarial".

Con ello lo que en un principio parecía claro, de una lectura completa de la sentencia no lo era tanto, puesto que no sólo había propia actividad respecto de las actividades correspondientes al ciclo productivo de la empresa principal sino también cuando lo que desempeñara la contratista fuera indispensable para conseguir el fin de aquélla así como cuando su actividad de no realizarla la tuviera que llevar a cabo el empresario principal.

Por tanto, la inseguridad volvía a plantearse puesto que una actividad será indispensable o no o perjudicará al empresario principal dependiendo del criterio del juzgador en cada caso. Y ello se puede demostrar con ejemplos como es el caso de la actividad de limpieza, que en ocasiones se ha estimado que sí que se da el requisito de la propia actividad (STSJ de Andalucía (Málaga) de 17 de enero de

33. En este sentido AA.VV. (Coord. QUESADA SEGURA, R.): Lecciones de Derecho del Trabajo. Madrid, 1994. Centro de Estudios Ramón Areces. Pág. 502; RODRIGUEZ PIÑERO, M.: "Propia actividad y contrata". RL, 1996, n 6. Pág. 8. 
1997 (Ar. 244) respecto de un hospital; STSJ de Cantabria de 16 de marzo de 1995 (Ar. 1059), en relaciôn con los colegios propiedad del Ayuntamiento de Torrelavega; STSJ de Andalucía (Sevilla) de 2 de junio de 1993 (Ar. 3091) respecto de una empresa dedicada al servicio de recaudación), basándose en lo necesaria que es esa actividad para el desempeño de las correspondientes actividades de cada una de las empresas principales, mientras que en otras la resolución ha sido la contraria (STSJ de Extremadura de 22 de octubre de 1996 (Ar. 3038), realizada en un centro comercial; STSJ de Galicia de 11 de enero de 1993 (Ar. 208), respecto del INEM y las Universidades de Santiago de Compostela; STSJ de Baleares de 5 de febrero de 1992 (Ar. 519), en relación con el INSALUD).

Con la finalidad de clarificar un poco más la cuestión se pronunció la STS (UD) de 24 de noviembre de 1998 (Ar. 10034) que al respecto señaló que caben dos interpretaciones:

a) la que entiende que propia actividad es la actividad indispensable, de suerte que integrarán el concepto, además de las que constituyen el ciclo de producción de la empresa, todas aquellas que resulten necesarias para la organización del trabajo;

b) la que únicamente integra en el concepto las actividades inherentes, de modo que sólo las tareas que corresponden al ciclo productivo de la empresa principal se entenderán propia actividad de ella.

La sentencia se inclina por estimar la segunda interpretación, con lo que en el concepto de propia actividad no tienen cabida las tareas complementarias. Resultaba la sentencia, por tanto, bastante clarificadora, puesto que "sólo quedarian incluidas (...) las actividades inherentes, y no aquellas actividades que, por más que puedan ser consideradas como indispensables o necesarias para la correcta ejecución del ciclo productivo o de servicios, no puedan recibir el calificativo de inherentes, al no estar directamente relacionadas con dicho ciclo"34.

Pero esa claridad desaparece cuando la sentencia a la hora de definir cuando se está ante actividades inherentes acoge una de las referencias indeterminadas de la sentencia de 18 de enero de 1995 al determinar que "nos encontrariamos ante una contrata de este tipo cuando de no haberse concertado ésta, las obras y servi-

34. DEL REY GUANTER, S.: "Actividad inherente, actividad indispensable y actividad complementaria en el art. 42 del TRET: notas a la luz de la STS de 24 de noviembre de 1998". Comunicación presentada en el X Congreso Nacional de Derecho del Trabajo y de la Seguridad Socia. Zaragoza, $28 \% 29$ de mayo de 1999. Ejemplar multicopiado. Pág. 7. 
cios debieran realizarse por el propio empresario comitente so pena de perjudicar sensiblemente su actividad empresarial", con lo que se estaba permitiendo incluir dentro del concepto de propia actividad no sólo las actividad inherentes sino también las necesariamente substituibles ${ }^{35}$. En consecuencia, lo que en un primer momento había aparecido como delimitado tras la inclusión de esta clarificación se ha vuelto a dar a la cuestión contornos indeterminados.

En cuanto a los pronunciamientos que se han dictado con posterioridad algunos de ellos han tendido a identificar propia actividad con actividad inherente al ciclo productivo. Así la STSJ de Cataluña de 29 de marzo de 1999 (Ar. 1744) entendió que no era propia actividad la actividad de mensajería que realizaba una contratista respecto de la Caja de Ahorros que la había contratado; la STSJ de CastillaLa Mancha de 21 de abril de 1999 (Ar. 808) en referencia a la actividad de rotular que desempeñaba una contratista respecto de la empresa principal que se dedicaba a la fabricación de neumáticos entendió que si era propia actividad, lo que si bien en un principio puede resultar extraño no lo es con posterioridad porque la empresa principal entre sus actividades inherentes tenía también la de distribución y venta de sus productos así como la preparación de los establecimientos para dicha finalidad, lo que incluía la coloración y plasmación de motivos propios (marcas y anagramas) de la empresa, que es de lo que se estaba encargando la contratista; o la STSJ de Galicia de 15 de abril de 1999 (Ar. 851) que estima que la limpieza no es propia actividad respecto de la que desempeñan las empresas principales, que es de explotación, comercialización y venta de carburantes y combustibles.

Por contra, otros pronunciamientos, acogiendo el argumento de la STS de 1995 y que luego reitera la STS de 1998 estiman que las actividades de reparación realizadas en una empresa dedicada a la siderurgia sí que son propia actividad basándose en que es una actividad accesoria pero imprescindible para que la empresa funcione.

Para concluir señalaré que en mi opinión, el criterio en virtud del que sólo son propias las actividades que sean inherentes al ciclo productivo es el que debe imperar a la hora de interpretar esta expresión si se quiere acabar con la indefinición que existe sobre el mismo y acotar de una vez la cuestión. Si bien la STS de 24 de noviembre de 1998 parece inclinarse por el mismo la inclusión de referencias de la STS de 1995 hacen que no sea lo clarificadora que en un principio parecía, con lo el camino parece que se ha avanzado pero todavía no está acabado

35. Id. ant. Pág. 7. 
siendo necesario un pronunciamiento determinante que al respecto consolide los términos que se están barajando a la hora de interpretarlo y que distinga ya no sólo entre actividad inherente $e$ indispensable -que es lo que hace la sentencia- sino también entre actividad inherente e imprescindible, lo que hasta el momento no se: observa pues se están utilizando ambos criterios indistintamente ${ }^{36}$.

\subsection{LA OBLIGACIÓN DE RECABAR INFORMACIÓN RESPECTO DE LOS FABRICANTES, IMPORTADO- RES Y SUMINISTRADORES}

La última obligación que debe observar en este caso el empresario principal viene regulada en el párrafo cuarto del art. 24 de la LPRL que al efecto señala que "las obligaciones consignadas en el último párrafo del apartado 1 del artículo 41 de esta Ley serán también de aplicación, respecto de las operaciones contratadas, en los supuestos en que los trabajadores de la empresa contratista o subcontratista no presten servicios en los centros de trabajo de la empresa principal, siempre que tales trabajadores deban operar con maquinaria, equipos, productos, materias primas o útiles proporcionados por la empresa principal".

De la lectura de este precepto dos conclusiones se pueden deducir:

$1^{\circ}$. Que se está haciendo referencia a contratas o subcontratas que se van a desempeñar fuera del centro de trabajo de la empresa principal, con lo cual se disponen unas obligaciones respecto de un supuesto de hecho diferente del que hasta el momento se estaba estudiando que partía de la premisa de que varias empresas compartían en el desempeño de sus funciones en un mismo lugar de trabajo.

$2^{\circ}$. Que se está disponiendo una obligación que lógicamente, en vista de que no se comparte centro de trabajo, nada tiene que ver con la propia actividad que se pueda dar entre la empresa principal y la contratista o subcontratista.

Por tanto, como esos contratistas o subcontratistas van a operar con máquinas, equipos o materias primas suministrados por la empresa principal, ésta deberá informar sobre su utilización correcta y adecuada de forma que no suponga un riesgo para la seguridad y salud, información que en todo caso habrá recabado de los fabricantes, importadores o suministradores de esos utensilios o productos, con lo que hay una equiparación entre el empresario principal y los sujetos de los quèe

36. Sobre las distinciones de los mismos vid DEL REY GUANTER, S.: "Actividad inherente, actividad indispensable y actividad complementaria... ${ }^{n}$ op. cit. Págs. 6 y ss. 
recoge la información ${ }^{37}$. Pero estimo que sólo con informar no es suficiente sino que deberán encargarse de que la utilización sea correcta, proporcionando los medios adecuados a los contratista.

Esa información del empresario principal al contratista o subcontratista deberá ser traspasada a los trabajadores de éstas últimas que son los que en última instancia utilizarán los medios suministrados por la comitente.

\section{BIBLIOGRAFIA}

-AA.VV. (Dir. SAlA FRANCO, T.): Derecho del Trabajo. Valencia, 1999 (12² ed.). Tirant lo Blanch.

-AA.VV. (Coord. QUESADA SEGURA, R.): Lecciones de Derecho del Trabajo. Madrid, 1994. Centro de Estudios Ramón Areces.

-AA.VV. (Coord. SALVADOR PÉREZ, F.): La seguridad y salud en el trabajo en la nueva Ley de Prevención de Riesgos Laborales. Sevilla, 1997. Junta de Andalucía.

-AA.VV. (Coord. ESCUDERO RODRÍGUEZ, R.): La Ley de Prevención de Riesgos Laborales. Málaga, 1997. Consejo Andaluz de Relaciones Laborales.

-AA.VV. (Coord. CASAS BAAMONDE, M.E., PALOMEQUE LÓPEZ, M.C. Y VALDÉS DAL-RÉ, F.): Seguridad y salud en el trabajo. Madrid, 1997. La Ley-Actualidad.

-AA.VV. (Dir. GARCIA NINET, J.I.): Lecciones sobre la Ley de Prevención de Riesgos Laborales. Castellón, 1997. Universitat Jaume I.

-AA.VV. (Coord. MONEREO PÉREZ, J.L.): La reforma del mercado de trabajo y de la seguridad social y salud laboral. Granada, 1996. Universidad de Granada.

-ALFONSO MELLADO, C.L.: Responsabilidad empresarial en materia de seguridad y salud laboral. Valencia, 1998. Tirant lo Blanch.

-ALONSO OLEA, M. Y BARREIRO GONZÁLEZ, G.: El Estatuto de los Trabajadores. Texto, comentarios y jurisprudencia. Madrid, 1995 ( $4^{2}$ ed.). Civitas.

-ÁLVAREZ DE LA ROSA, M.: "El deber de protección y los servicios de prevención de riesgos laborales". Revista Derecho y Salud, 1996, $\mathrm{n}^{\circ} 1$.

-APARICIO TOVAR, J.: "Las obligaciones del empresario de garantizar la salud y la seguridad en el trabajo". REDT, 1991, n 49.

-BLASCO PELLICER, A. Y MORRO LÓPEZ, J.J.: "Puntos críticos en torno al recargo de prestaciones por falta de medidas de seguridad e higiene en el trabajo. Reflexiones en torno a la incidencia de la Ley de Prevención de Riesgos Laborales". TrS, 1995, n 60.

37. Así se han pronunciado GONZÁlEZ ORTEGA, S. Y APARICIO TOVAR, J.: Comentarios a la Ley 31/1955, de Prevenciōn... op. cit. Pág. 166; y GOERLICH PESET, J.M.: "Coordinación de actividades empresariales..." op. cit. Pág. 154. 
-CARDONA RUBERT, M.B.: Datos sanitarios y relación laboral. Valencia, 1999. Tirant lo Blanch.

-CRUZ VILLALÓN, J.: "Descentralización productiva y responsabilidad laboral por contratas y subcontratas". RL, 1992, $\mathrm{n}^{\circ} 2$.

-CRUZ VILLALÓN, J.: "Outsourcing. Contratas y subcontratas". Ponencia presentada en el X Congreso Nacional de Derecho del Trabajo y de la Seguridad Social. Zaragoza, 28 y 29 de mayo de 1999.

-DEL REY GUANTER, S.: "Actividad inherente, actividad indispensable y actividad complementaria en el art. 42 del TRET: notas a la luz de la STS de 24 de noviembre de 1998". Comunicación presentada en el X Congreso Nacional de Derecho del Trabajo y de la Seguridad Socia. Zaragoza, 28 y 29 de mayo de 1999.

-FERNÁNDEZ MARCOS, L.: La seguridad e bigiene del trabajo como obligación contractual y como deber público. Madrid, 1975. Servicio de Publicaciones del Ministerio de Trabajo. -FERNÁNDEZ MARCOS, L.: “Responsabilidad del empresario principal respecto de contratas y subcontratas en materia de seguridad e higiene en el trabajo". AL, 1992, $\mathbf{n}^{\circ} 1$.

-GARCÍA PIQUERAS, M.: Régimen jurídico de las responsabilidades empresariales en las contratas y subcontratas de obras y servicios. Valencia, 1998. Tirant lo Blanch.

-GOERLICH PESET, J.M.: "Coordinación de actividades empresariales y prevención de riesgos laborales". AL, 1997, $\mathrm{n}^{\circ} 8$.

-GONZÁLEZ LABRADA, M.: Seguridad y salud en el trabajo y responsabilidad contractual del empresario. Barcelona, 1996. CEDESC.

-GONZÁLEZ ORTEGA, S.: "Derecho a la salud y control de los trabajadores". RL, 1990, n' 56.

-GONZÁLEZ ORTEGA, S. Y APARICIO TOVAR, J.: Comentarios a la ley 31/1995 de Prevención de Riesgos Laborales. Madrid, 1996. Trotta.

-GONZÁLEZ-POSADA MARTÍNEZ, E.: "La prevención de riesgos laborales: funciones, contenido y efectos". Ponencia del VII Congreso Nacional de Derecho del Trabajo y de la Seguridad Social. Valladolid, 24 y 25 de mayo de 1996 (ejemplar multicopiado).

-MARTÍN ARTILES, A: Flexibilidad y relaciones laborales. Estrategias empresariales y acción sindical. Madrid, 1995. Consejo Económico y Social

-MARTÍN VALVERDE, A.: "Responsabilidad empresarial en caso de subcontrata de obra y servicios". En AA.VV. (Dir. BORRAJO DACRUZ, E.): El Estatuto de los Trabajadores. Comentarios a las leyes laborales (tomo VII). Madrid, 1982. EDERSA.

-MARTÍNEZ EMPERADOR, R.: El Estatuto de los Trabajadores y la responsabilidad empresarial en caso de subcontratas de obras $y$ servicios. IES Madrid, $s / f$. Servicio dé Publicaciones del Ministerio de Trabajo.

-MOLINER TAMBORERO, G.: "La responsabilidad civil empresarial derivada del incumplimiento de las previsiones contenidas en la Ley 31/1995, de prevención de riesgos laborales". AL, 1996, n' 19.

-MONEREO PÉREZ, J.L.: El recango de prestaciones económicas por incumplimiénito de meatidas de seguridad e bigiene en el trabajo. Madrid, 1992. Civitas.

-MONEREO PEREZ, J.L.: La responsabilidad empresarial en los procesos de subcontratacton: puntos críticos. Madrid, 1993. Ibídem. 
-MONTOYA MELGAR, A. Y PIZÁ GRANADOS, J.: Curso de seguridad y salud en el trabajo. Madrid, 1996. McGraw-Hill.

-PÚRCALLA BONILLA, M. A.: "Notas sobre la naturaleza jurídica del recargo de prestaciones por incumplimiento de medidas de seguridad e higiene en el trabajo". RTSS, 1995, abrilmayo.

-RODRÍGUEZ PIÑERO, M.: "La regulación protectora del trabajo en contratas". RPS, 1972, nº 93.

-RODRÍGUEZ PIÑERO, M.: "Propia actividad y contrata". RL, 1996, nº 6.

-SALA FRANCO, T. Y ARNAU NAVARRO, F.: Comentarios a la Ley de Prevención de Riesgos Laborales. Valencia, 1996. Tirant lo Blanch.

-SÁNCHEZ CUBEL, D.: Todo sobre la nueva Ley de Prevención de Riesgos Laborales. Barcelona, 1996. Praxis.

-SEMPERE NAVARRO, A.V., GARCÍA BLASCO, J., GONZÁLEZ LABRADA. M. Y CARDENAL CARRO, M.: Derecho de la seguridad y salud en el trabajo. Madrid, 1996. Civitas.

-VALVERDE ASENCIO, A.J.: La responsabilidad administrativa laboral en los supuestos de pluralidad de empresarios. Valencia, 1997. Tirant lo Blanch. 